NEWS

\title{
Cash interests taint drug advice
}

Researchers and physicians who write the rules on prescribing drugs have extensive financial connections with the pharmaceutical industry, an investigation by Nature has revealed. Public-health experts say that the results of the survey, which is the largest of its kind, suggest that drug companies are distorting decisions about how their products are being prescribed.

In the investigation of the panels that write clinical guidelines - documents that govern the diagnosis and treatment of patients Nature found that more than one-third of authors declared financial links to relevant drug companies, with around $70 \%$ of panels being affected. In one case, every member of the panel had been paid by the company responsible for the drug that was ultimately recommended.

These links with pharmaceutical companies are more worrying than the financial conflicts known to plague clinical trials and reviews, say public-health experts, because the guidelines have such a direct effect on the drugs that doctors prescribe. ${ }^{\alpha}$ The guidelines are specifically written to influence the practice of many physicians," says Niteesh Choudhry, a specialist in health policy at Harvard Medical School. "The effects of conflicts may be translated many times over to patients."

"The numbers in the survey are distressing", agrees Drummond Rennie, deputy editor of the Journal of the American Medical Association and an advocate of proposals to free guidelines from industry influence. "Drugcompany sponsors see guideline-issuing bodies as perfect places to exert influence. The practice stinks."

\section{Misguided?}

The guidelines have moved on to doctors' radar screens over the past decade or so, in line with an increased emphasis on using 'evidence-based' methods to treat patients. Many major professional bodies around the world, such as the American College of Physicians, now publish several guideline documents every year. The advice is based on the results of clinical trials, and tells doctors which drugs to prescribe and when.

In its survey, Nature studied more than 200 guidelines from around the world that were deposited with the US National Guideline Clearinghouse in 2004. Only 90 contained details about individual authors' conflicts of interest. Of those, just 31 were free of industry influence.

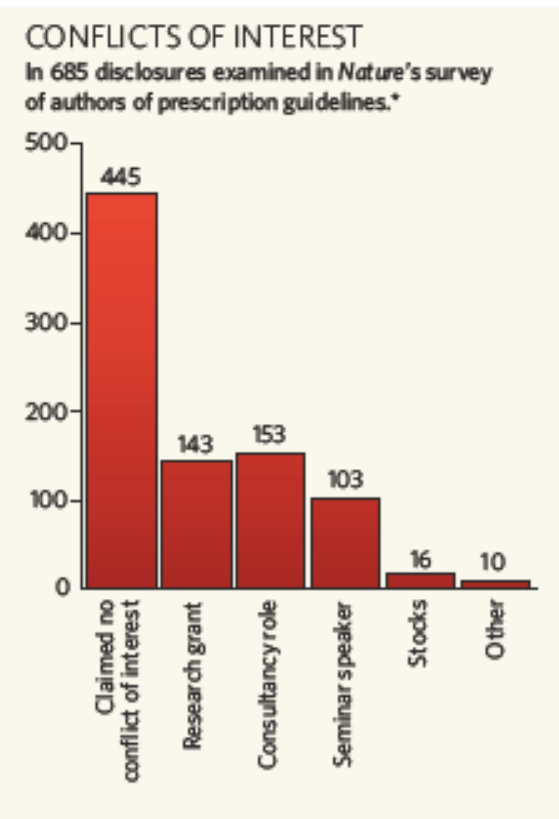

$35 \%$ of authors said they had a conflict of interest of some kind.

16 authors helped to write guidel ines on illnes ses relevant to companies in which they owned stock.

$49 \%$ of guidelines did not include any details of authors' conflicts of interest.

For full survey results, see

wwwnaturecom/news/2005/051017/fullV 4371070a.html

"Some of the authors had more than one conflict of interest

Half of those that gave individual details had at least one author with a conflicting advisory position in the pharmaceutical industry. More than a third of the panels included at least one member who gave seminars on behalf of a relevant drug company. And one in ten contained a member who owned stock in a company with products being considered.

The latter type of conflict is especially worrying, says Bruce Fye of the Mayo Clinic in Rochester, Minnesota, who raised the issue of guideline ethics during his presidency of the American College of Cardiology in 2002-3. Prescription practices promoted by guidelines can have a direct effect on drug sales and thus stock price. "Stock options should be viewed as unacceptable," he says.
In one example uncovered by Nature, guidelines for the treatment of anaemia in HIVpositive patients were written by a working group selected by Paul Volberding, a leading AIDS researcher and physician, and vicechairman of the Department of Medicine at the University of California, San Francisco. Volberding convened the group at the request of Ortho Biotech, a pharmaceutical company based in Bridgewater, New Jersey. Ortho Biotech funded the group's meetings, and all six members, including Volberding, had been paid by the company for lecturing or consultancy jobs. The group's latest guidelines, published last year (P. Volberding et al. Clin. Infect. Dis. 38, 1454-1463; 2004), recommend the use of epoetin alpha, a drug marketed by Ortho Biotech.

\section{Slippery stats}

Physicians' organizations say that one or two authors with a conflict of interest could not influence a panel containing tens of members. But assessing just how many authors have such conflicts is difficult. In the Nature survey, $35 \%$ of the 685 authors involved declared conflicting industry links (see graphic). Experts say that this is likely to be an underestimate, however, because it relies on authors' own declarations.

For example, the Center for Science in the Public Interest (CSPI), based in Washington DC, examined the disclosure statements on some randomly chosen blood-pressure guidelines published last year. Only one author declared a conflict of interest, but further checks by the CSPI revealed that four other authors had failed to disclose research funding from relevant drug companies.

The problem could be even worse in guidelines that don't contain conflict-of-interest declarations, warns Merrill Goozner, director of the CSPI's Integrity in Science project. "It is

\section{"It's not true that} people can remain completely objective." usually the journals and supplements that rely heavily on industry advertising that are least likely to have good disclosure policies."

The organizations that produce guidelines argue that industry links do not necessarily lead to biased advice. Some employ review panels to check prospective guidelines although conflicts of interest are just as likely to occur in review panels. And authors insist that they are careful to avoid bias. "We realized this would be a concern and so looked very 
carefully at our recommendation," says Volberding of the HIV guidelines. "The committee really was independent in its deliberations."

Critics say that the influence exerted by industry money is unconscious but powerful. Funding for conference travel and accommodation has been linked with increased requests for a sponsor's drug, for example. And meetings with drug reps both decrease physicians' ability to spot erroneous claims about medications and increase their requests for new drugs with no demonstrated advantage over generics (A. Wazana J. Am. Med. Assoc. 283, 373-380; 2000).

"It's not true that people can remain completely objective," says Peter Gøtzsche, director of the Nordic Cochrane Centre in Copenhagen, Denmark, which runs independent reviews of drug efficacy.

Gøtzsche and others want guidelines to be prepared in ways that reduce the potential for bias. Some such schemes already exist. In Britain, for example, guidelines are provided by a government-funded body called the National Institute for Health and Clinical Excellence (NICE). Although some of the experts used by NICE have industry links, the institute itself is independent of industry and consults with other stakeholders, such as patients' groups.

\section{Expert witnesses}

In the United States an alternative process is being used for conditions where there is conflicting evidence as to the best treatment. Experts in a particular condition - those most likely to have relevant industry links are used as witnesses, but the panel members themselves are chosen for their skills at examining medical data. "If you have a conflict of interest you can't be on the panel," says Susan Rossi, deputy director of the Office of Medical Applications of Research at the National Institutes of Health, which runs the scheme.

But the bodies that produce guidelines maintain that there just aren't enough experts without conflicts of interest. Nathaniel Clark of the American Diabetes Association estimates that three-quarters of members eligible to write guidelines have industry links, and other organizations report a similar number.

The latest figures underline the urgency of breaking the deadlock. In 2002, Choudhry and colleagues found similar levels of conflicts of interest, but he says that physicians have since assumed that disclosing conflicts is all that is required to solve the problem. With drugcompany stock-holders still sitting on the panels that make prescription decisions, Choudhry warns: "We need a better way to deal with conflicts of interest."

Rosie Taylor and Jim Giles

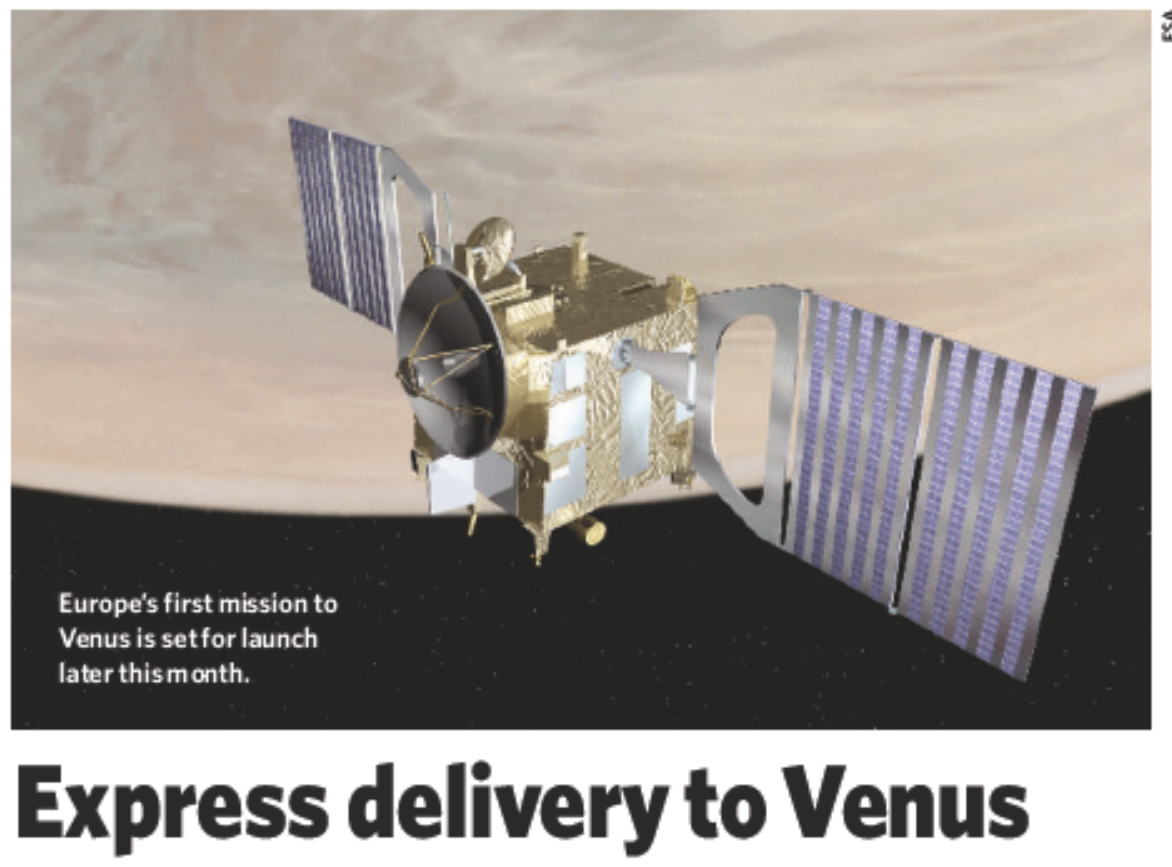

Get set for a revival of interest in Earth's wayward twin. The European Space Agency (ESA) plans to launch Venus Express next week - the first visit to the planet in more than a decade. The focus of the $€ 220$-million (US\$265-million) mission will be the planet's thick atmosphere, which some think could host exo tic life forms that use ultraviolet instead of visible light.

Venus Express will begin its journey from Kazakhstan on a Soyuz-Fregat rocket; the month-long launch window opens on 26 October. ESA developed the mission - its first to Venus - in less than four years, after asking the science community for ideas on adapting its Mars Express spacecraft for another purpose.

The craft uses cameras and spectrometers adapted from Mars Express and Rosetta, an upcoming comet mission. These will build up a three-dimensional profile of Venus's carbon dioxide-rich atmosphere, which traps heat and drives temperatures on the surface to a searing $450^{\circ} \mathrm{C}$. Past missions, including the 1978 Pioneer Venus orbiter and the Magellan surface-mapper of the 1990s, have hinted at active volcanism and lightning on the planet; Venus Express will investigate these observations further.

The mission may also help to determine what is absorbing ultraviolet radiation in the planet's clouds. David Grinspoon of the Southwest Research Institute in Boulder, Colorado, and others speculate that life may have evolved that thrives in acidic environments and photosynthesizes ultraviolet light. Rather than living on the hot surface, such organisms might reside in long-lived clouds, where temperatures and pressures are more Earth-like.

Grinspoon has been modelling the history of Venus's atmosphere, and his preliminary results indicate that the planet's early ocean could have persisted for as long as 2 billion years. Life could have adapted to the clouds when the surface water disappeared, he suggests.

Grinspoon calls this a kind of "thought experiment", and does not claim there is evidence for life on Venus today. Nor does he believe that terrestrial microbes stowing away on Venus Express risk contaminating the planet. Current international guidelines for planetary protection require sterilization for Mars-bound spacecraft, but not for tho se headed for hot and acidic Venus.

Still, NASA has asked the US National Academy of Sciences, based in Washington DC, to revisit the subject of planetary protection for Venus. Thirty years have passed since it last looked at the question, says NASA planetary-protection officer John Rummel. At present, the agency is mulling over ideas for samplereturn missions to Venus, and the academy has recommended that a lander be sent to the planet in the next decade.

In the meantime, Japan plans to launch its Venus Climate Orbiter in 2008, and two Mercury-bound spacecraft MESSENGER and BepiColombo - will study Venus during brief fly-bys. Tony Reichhardt 